Natural Hazards and Earth System Sciences (2003) 3: 299-309

(C) European Geosciences Union 2003

\title{
Tsunami generation in Stromboli island and impact on the south-east Tyrrhenian coasts
}

\author{
S. Tinti, G. Pagnoni, F. Zaniboni, and E. Bortolucci \\ Dipartimento di Fisica, Università di Bologna, Bologna, Italy \\ Received: 2 August 2002 - Revised: 17 October 2002 - Accepted: 18 October 2002
}

\begin{abstract}
Stromboli is one of the most active volcanoes in the Aeolian island arc in south Tyrrhenian sea, Italy. In the last 100 years the most relevant volcanic eruptions have been accompanied by local tsunamis, that have caused damage and casualties. In some cases the direct mechanism of local tsunami generation is clear, i.e. pyroclastic flows entering the sea. In some others it is uncertain and some speculation concerning the collapse of the eruptive column on the sea surface or the failure of some underwater mass can be made. But the ordinary activity is unlikely to generate large regional tsunamis. These can be produced by the lateral collapse of the volcanic cone that geomorphological and volcanological investigations have proven to have occurred repeatedly in the recent history of the volcano, with return period in the order of some thousands of years. The last episode is dated to less than $5 \mathrm{ka}$ BP, and left the Sciara del Fuoco scar on the north-west flank of Stromboli.

Based on previous studies, the possible collapse of the nort-western sector of Stromboli and the consequent generation and propagation of a tsunami are explored. The impact on Stromboli and on the other islands of the Aeolian archipelago is estimated, as well as the impact on the coast of Sicily and the Tyrrhenian coasts of Calabria. The simulation is carried out by means of a double model: a Lagrangian block model to compute the motion of the collapsing mass, and a finite-element hydrodynamic model to compute the evolution of the tsunami. Two distinct tsunami simulations are carried out, one on a very fine grid around the source region to evaluate the tsunami near Stromboli, and one utilising a coarser grid covering the whole south-east Tyrrhenian sea to compute the tsunami propagation toward Sicily and Calabria. It is found that a huge-volume collapse of the northwestern flank of the Stromboli cone is capable of producing a regional tsunami which is catastrophic at the source and
\end{abstract}

Correspondence to: S. Tinti (steve@ibogfs.df.unibo.it) devastating on long stretches of Tyrrhenian coasts, but particularly in the neighbouring islands of Panarea and Salina, and along the Calabria coasts around Capo Vaticano.

\section{Introduction}

Stromboli is the youngest stratovolcano of the Aeolian islands and is located at the margin of the abyssal plain in the southern Tyrrhenian sea. It is the northernmost island of the volcanic arc (see Fig. 1). It is characterised by a persistent activity with moderate rhythmic explosions that is named "strombolian" by volcanologists, and by occasional more energetic paroxysmic phases also with lava effusion and fountains and pyroclastic flows occurring at intervals of several years or decades (Rosi et al., 2000). The volcanic activity of Stromboli was known to ancient Greeks, according to Mercalli (1881). Its eruption history however is much shorter, for the first chronological available record refers to the major explosion of 1558 as reported in the catalogue by Imbò (1965) and in the list of the Strombolian eruptions due to Barberi et al. (1993). Very likely the catalogue of eruptions is complete only since the end of the 19th century; that is since the first systematic studies on the volcano and on its activity were undertaken by Mercalli and his collaborators (see for example the surveys of the 1888-91 activity by Mercalli, 1891, and by Riccò and Mercalli, 1892).

Accounts on tsunamis associated with Stromboli activity are known only since the last century and are associated with the largest eruptions (Tinti and Maramai, 1996): they have been of moderate size, but have caused damage and casualties on the local coasts of Stromboli. Though the relation between the observed tsunamis and the volcanic activity is unquestionable, the direct genetic mechanism of such events is generally uncertain. Only for the 11 September 


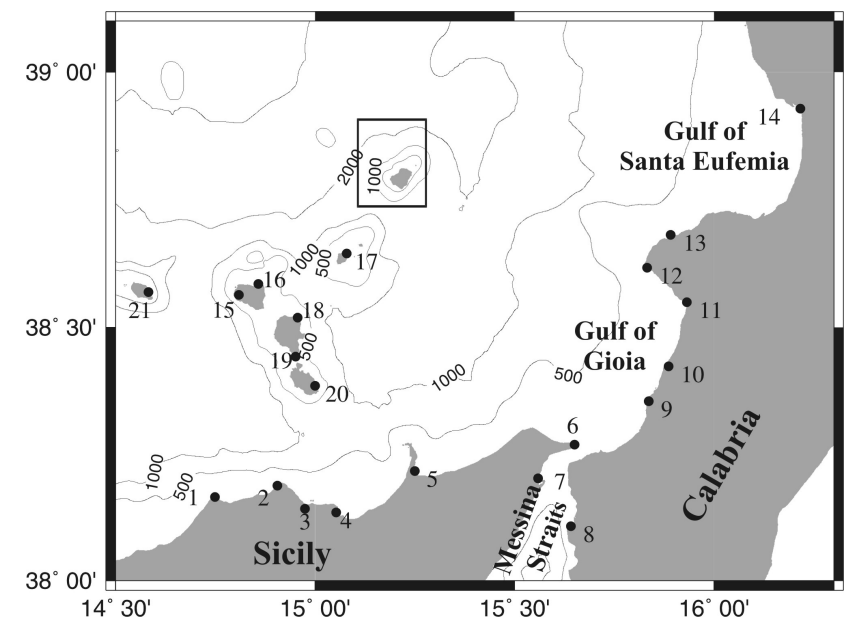

Fig. 1. Map of the south-eastern Tyrrhenian region including most of the Aeolian archipelago and bordered by Calabria (to the east) and by Sicily (to the south). The entire region, except for the small marine area at the lower right corner is covered by the grid used for the tsunami simulation in the far field. The rectangle surrounding Stromboli is the area where the near-field tsunami simulation has been carried out. Bathymetry labels are in metres. The numbers correspond to the localities listed here. On Sicily coast: 1Capo d'Orlando, 2- Capo Calavà, 3- Patti, 4- Tindari, 5- Milazzo, 6- Punta Faro, 7-Messina; On Calabria coast: 8- Reggio Calabria, 9- Palmi, 10- Gioia Tauro, 11- Nicotera, 12- Capo Vaticano, 13Tropea, 14- Lamezia; On Aeolian islands: 15- west Salina, 16- east Salina, 17- Panarea, 18- north Lipari, 19- south Lipari, 20- Vulcano, 21- Filicudi.

1930 eruption a straightward connection between dense pyroclastic flows and a local water wave can be established with certainty: the flows travelled down the deep valley named Vallonazzo and entered the sea at the northern coasts north of San Bartolo (see Rittmann, 1931; Abbruzzese, 1936; Tinti and Maramai, 1996). For the other cases, some speculations can be made on the possible tsunamigenic role (1) of submarine landslides triggered by the paroxysmic activity shaking the whole volcanic edifice and (2) of the impact of the collapsing eruptive column on the sea surface. This latter mechanism has been suggested by Ponte (1921) to explain the 1919 tsunami, and deserves careful attention. It is interesting to point out that the 1919 tsunami, though it was small and only of intensity 3 according to the Sieberg-Ambraseys scale (see Ambraseys, 1962), nonetheless it was observed in the whole southern Tyrrhenian sea, and recorded by tide gauges installed in Sicily, namely at Faro and in the Messina harbour (Platania, 1922; Tinti and Maramai, 1996). Accounts on tsunami impact on the coasts of Stromboli and on damage produced by the waves to boats of local people suggest that the wave amplitude at the source was in the order of a few meters. At Faro, some $80 \mathrm{~km}$ south of Stromboli, the record oscillations have $8-10 \mathrm{~min}$ period and height of about 5-7 cm, well distinguishable from the background noise due to the sea agitation of meteorological origin. This testifies that tsunamis generated in Stromboli have potential to prop-

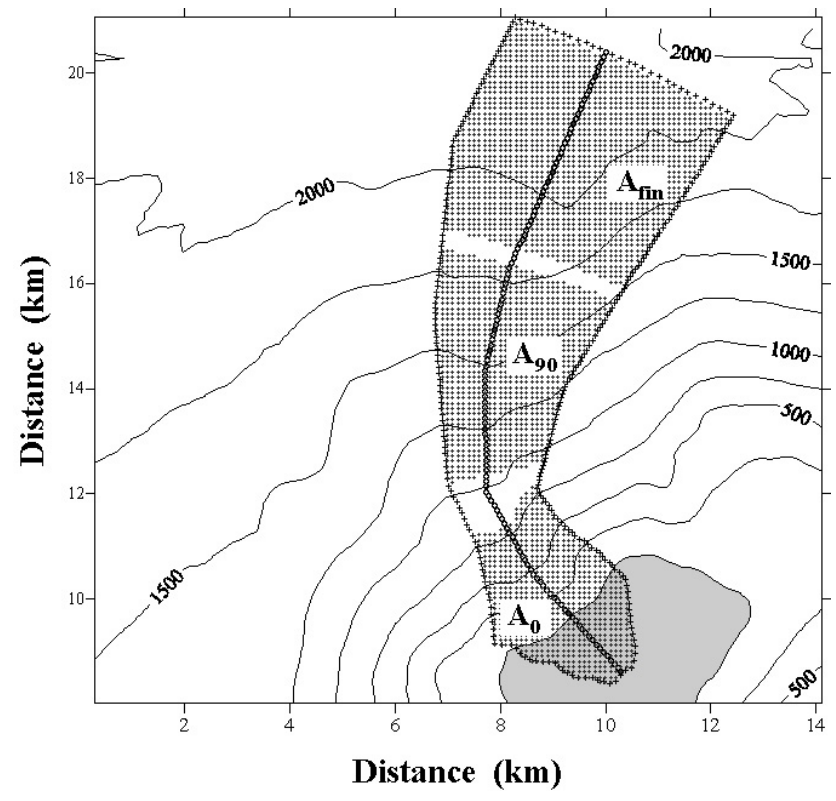

Fig. 2. Geometry of the landslide model. The sliding surface is delimited by the lateral boundary curves (solid crosses). The predefined common trajectory of the block is the inner curve (open circles). The initial basal area of the body is A0 and corresponds to the hypothesis A formulated by Kokelaar and Romagnoli (1995). The landslide is partly subaerial and partly submarine. The basal areas $\mathrm{A}_{90}$ and $\mathrm{A}_{\text {fin }}$ calculated respectively at $t=90 \mathrm{~s}$ and at the final computation time $t=167 \mathrm{~s}$ are also shown. The body spans the sliding surface during its motion changing accordingly its shape. Sea depth contour lines are in metres.

agate far from the source reaching the coasts of Sicily and the Italian mainland.

As we have seen, tsunamis produced by the largest explosions of Stromboli can be damaging at the source, but not in the far field, where they arrive in form of small sea-level perturbations. However, recent research has recognised that Stromboli has also potential to produce large catastrophic tsunamis, which can be the consequence of the lateral collapse of the volcanic cone. The main purpose of this paper is to analyse the tsunami generated by a possible sector collapse of Stromboli and to study its propagation in the southern Tyrrhenian sea: the paper will examine how the tsunami will affect not only Stromboli, but also the other islands of the Aeolian archipelago and the coasts of Calabria and Sicily. This study will address first the problem of the flank collapse of the Stromboli edifice and of its numerical simulation through a Lagrangian-type block model, then it will compute the associated tsunami by means of a finite-element Eulerian solver of the shallow-water equations applied (1) over a grid covering the near field around the island and (2) over a larger grid embracing the entire south-eastern Tyrrhenian. More emphasis will be put on this last issue, that is on the calculation and on the discussion of the tsunami in the large scale. We anticipate here that the main result of this research is that the tsunami energy radiation is almost isotropic around 


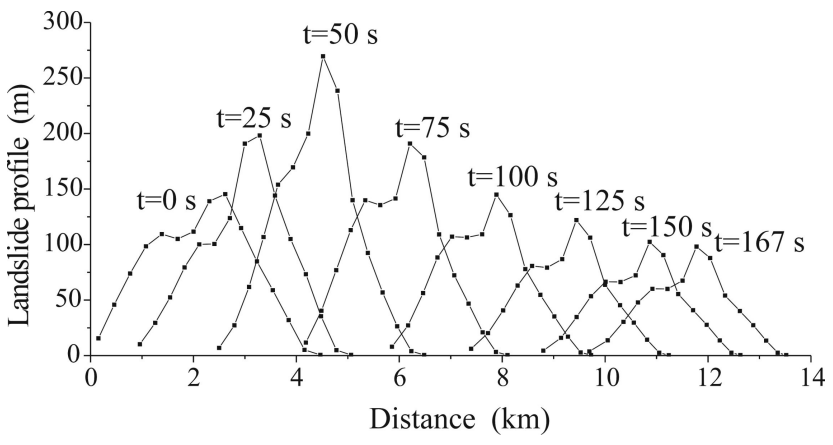

Fig. 3. Profiles of the landslide taken along the curvilinear trajectory computed at various times. The time $t=0$ corresponds to the beginning of the body motion. Solid squares show the heights of the blocks forming the slide and are placed in the positions corresponding to the co-ordinate of the center of mass of each block. The number of blocks is 15 .

the source at intermediate times, but later when the front approaches the Calabrian coasts, the energy is focussed on the Capo Vaticano promontory which happens to be attacked by the highest waves.

\section{Collapses of Stromboli flank}

The last collapse of Stromboli was responsible of the formation of the Sciara del Fuoco (SdF) scar that is the main feature of the north-western sector of the island. Collapses have occurred frequently in the history of the volcano. As regards the period of the last $13 \mathrm{ka}$, which is the most studied and best known, evidence has been found of at least three other episodes of flank collapse that affected the same sector of the volcanic edifice with intermediate phases of cone growth and accumulation of volcanic deposit (Tibaldi, 2001). The first of these collapses involved the Upper Vancori about 13 ka BP (Tibaldi et al., 1994) with an estimated volume exceeding $2 \mathrm{~km}^{3}$, and was followed by the gradual building of the Neostromboli that collapsed in the early Holocene more than $5.6 \mathrm{ka}$ BP (Gillot and Keller, 1993) with a sliding mass in the order of $1 \mathrm{~km}^{3}$ (Tibaldi, 2001). The Neostromboli depression was later filled by the cone of Pizzo Sopra La Fossa whose collapse can be dated less than 5000 years ago. The last cycle of cone formation and failure produced the $\mathrm{SdF}$ that is certainly younger than the Pizzo Sopra La Fossa, though its age cannot be determined better ( $<5 \mathrm{ka} \mathrm{BP})$. The recurrence of collapses affecting the same sector of Stromboli has been explained by means of a number of concomitant factors, the most important of which are (Kokelaar and Romagnoli, 1995; Tibaldi, 2001): (1) the volcanic edifice periodically reaches a stage of critical mass overloading and of constructional oversteeping, leading to conditions of gravitational instability; (2) regional tectonic lineaments control the morphostructural developments of preferentially NE-SW trending weakness zones consisting of systems of eruptive fissures and fractures, magma intrusion and dyking, with consequent

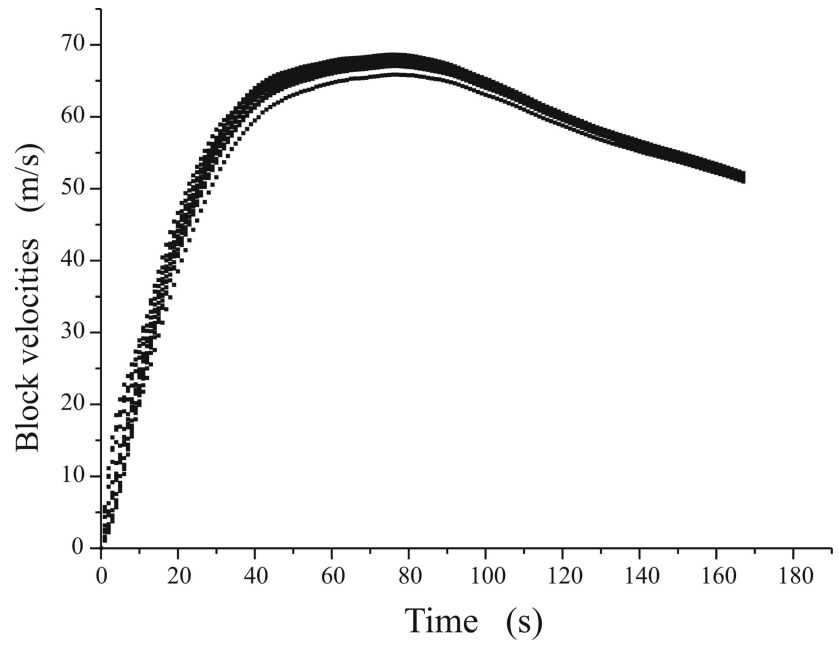

Fig. 4. Velocities of the blocks vs. time. Blocks move at different speed at all times. Notice that the computation is stopped when all blocks have still high speed, since the tsunamigenic potential of the slide moving in deep ocean at this later stage is strongly reduced.

dilation and outward displacement of the flank of the volcano; (3) the Tyrrhenian sea bottom on which the volcanic edifice is located is asymmetric and deeps substantially towards north-west, reaching depths larger than $3200 \mathrm{~m}$ in the Marsili Basin (Kidd et al., 1998), which makes the NW flank more prone to instability than the SE one. It is interesting also to note that the investigations on the recent sequence of four collapses found that their upper scarps are concentric, with the youngest being internal and show that the areas and volumes involved by the failures tend to decrease with their age, suggesting that each failure tends to affect at most the material extruded since the previous collapse and that the thickness of the collapsing body tends to become smaller, or, equivalently, that the basal sliding surface tends to become more surficial (Tibaldi, 2001).

\section{Modelling of the Sciara del Fuoco lateral collapse}

In this paper we will focus on the last major slope failure of Stromboli, that is on the lateral collapse that occurred less than $5 \mathrm{ka} \mathrm{BP}$ producing the SdF scar that is still visible today. The total volume of material involved is estimated to be in the range $0.52-0.95 \mathrm{~km}^{3}$ by Tibaldi (2001), while Kokelaar and Romagnoli (1995) suggest the involvement of a larger volume, advancing two possible hypotheses on the position of the sliding surface: a detachment surface giving a removed volume of about $1 \mathrm{~km}^{3}$ and a maximum thickness in the order of $150 \mathrm{~m}$ (hypothesis A); and a deep-seated surface implying a maximum landslide thickness of about $800 \mathrm{~m}$ and corresponding to circa $1.8 \mathrm{~km}^{3}$ (hypothesis $\mathrm{B}$ ). In a previous study Tinti et al. (2000) used hypothesis A, and this choice seems to be convenient also for the present analysis, since it is a good compromise between Kokelaar-Romagnoli's maximum and Tibaldi's estimates. The simulation of the motion 

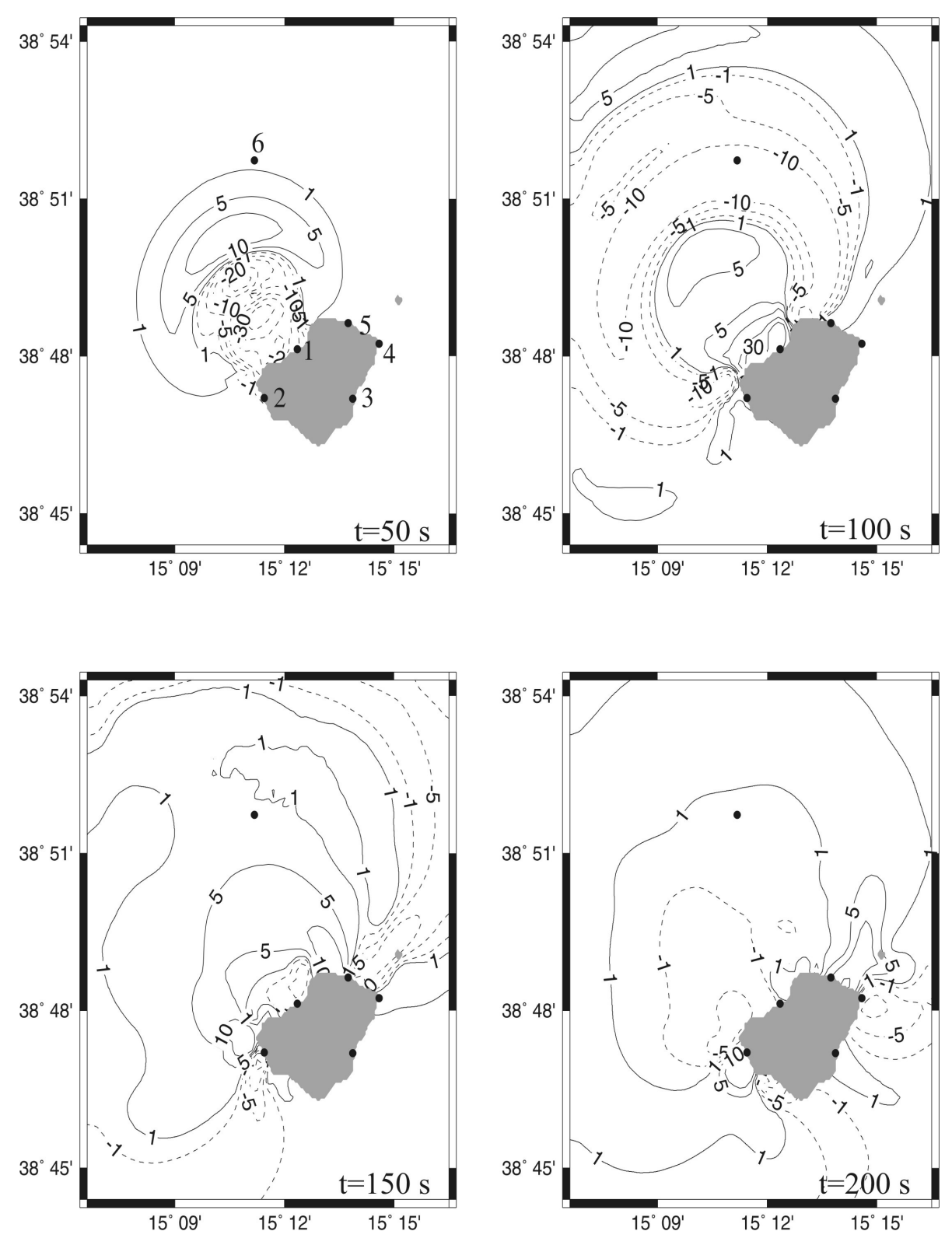

Fig. 5. Water elevation fields around Stromboli calculated at various times. The area shown in the map corresponds to the area covered by the finite-element grid used for the near-field tsunami simulation. Contour lines are labeled in metres. Solid circles and the related numbers (see the upper left panel) denote the grid nodes where sea level time histories are computed. These correspond to the following places: 1- Sciara del Fuoco, 2- Ginostra, 3- Malpasseddu, 4- Punta della Lena, 5- Scalo dei Balordi, 6- offshore node located on the slide path.

of the sliding body is computed by means of a numerical model based on a Lagrangian approach. We use here an updated code, the first version and subsequent variant of which have been described in detail by Tinti et al. (1997) and by Tinti et al. (2000), respectively. Here it is worth outlining only the main characteristics of the model. The body is considered as a chain of blocks sliding on a predefined track. The motion of each block is calculated by accounting for all the forces acting on it, namely the body forces (the force of gravity, the force of buoyancy if the block is partially or totally underwater), and the surface forces (the friction basal force, the resistance due to water, and the force of interaction with the neighbouring blocks). The blocks are allowed to change their shape during their motion, i.e. they may experience longitudinal/transversal extension or contraction, but they do not change their volume, which has the consequence that any variation of their basal area reflects in a corresponding change of their height. One of the advantages of the model is that it can deal easily with various rheologies since the internal forces are expressed in terms of a number of parameters that can be conveniently adapted to describing very compact undeformable rocks moving as rigid bodies as well as loose cohesionless debris avalanches (Tinti et al., 1998). Conversely, one limit of the model is that all blocks remain 

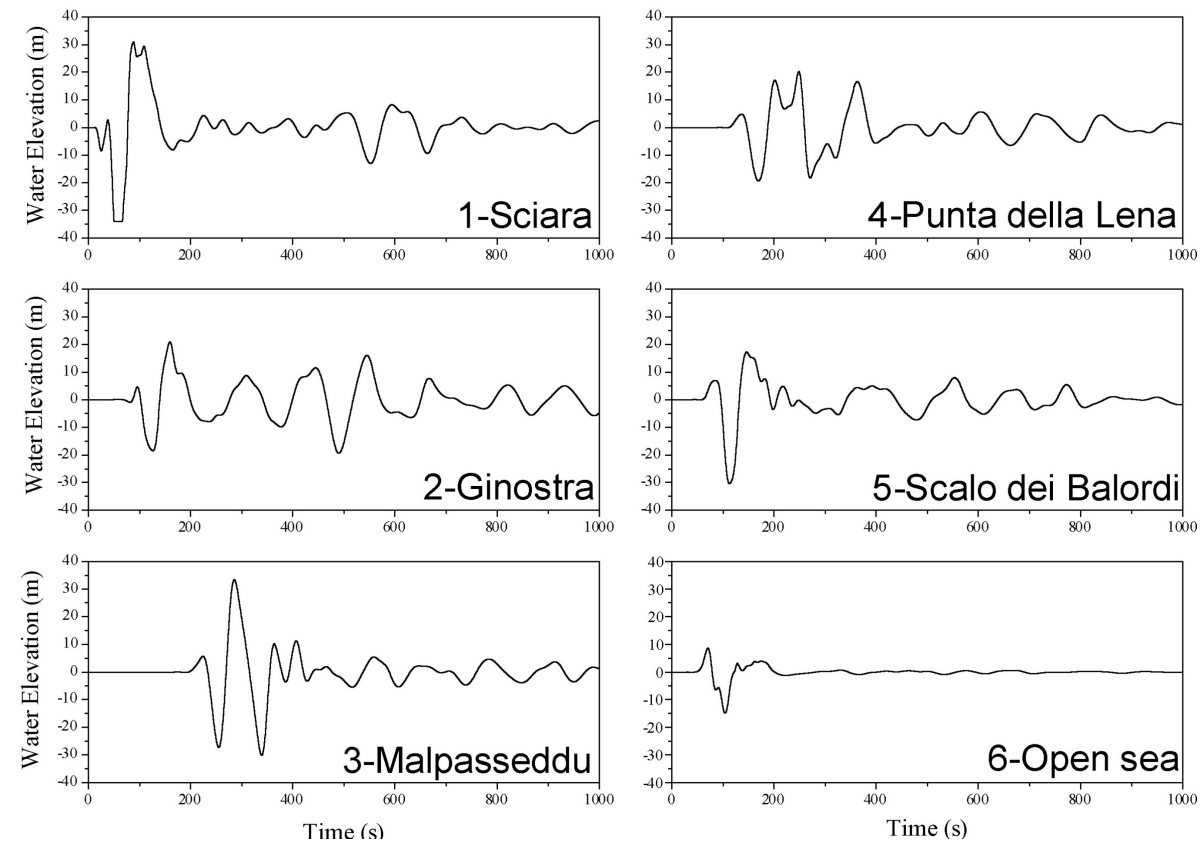

Fig. 6. Water elevation records calculated in the localities shown in the geographic maps of Fig. 5. The near-field simulation has been carried out for $1000 \mathrm{~s}$. Notice that the negative trough of the Sciara del Fuoco, that is the source region of the tsunami, is truncated at the lower value of $-35 \mathrm{~m}$, which corresponds to the assumed depth of all coastal nodes of Stromboli.

contiguous and cannot separate from one another during sliding, which means that it cannot handle landslides fractioning in distinct tongues nor the opposite case of various landslide merging in a unique flow.

The thickness and distribution of the collapsing body as well as the sliding surface were available from previous studies in digital form on a $100 \mathrm{~m} \times 100 \mathrm{~m}$ grid (Tinti et al., 2000). The SdF scar extends from the cone summit at about 800 a.s.l. down to 700 b.s.l. The initial body is partitioned into 15 blocks. The simulation is stopped about $167 \mathrm{~s}$ after its initiation when the slide reaches an ocean depth larger than $2000 \mathrm{~m}$, loosing most of its tsunamigenic potential. Figure 3 shows instantaneous profiles of the slide taken at various times along the predefined trajectory, while Fig. 4 shows altoghether the block velocities vs. time. It may be seen that in the first stage, corresponding to the first 40 seconds of motion, the body accelerates strongly attaining a peak velocity exceeding $60 \mathrm{~m} / \mathrm{s}$ and increasing its maximum height. Later it slows down progressively, due mostly to the resistant action of the water against the landslide front, and it reduces its height, owing to the seaward widening of the sliding surface in distal region (see Fig. 2). Notice further that the velocities of the blocks tend to have the same trend, though they differ from each other, with difference however becoming smaller as time elapses.

\section{The Tsunami around Stromboli}

The tsunami produced by a moving underwater body can be computed by solving the long-wave hydrodynamic equations including a term that accounts for the tsunami excitation induced by the landslide and that depends on the transient variation of the sea topography associated with the landslide motion and on the transfer function associated with the local sea depth and landslide size (see Tinti et al., 1999). The solution is performed by means of the finite-element technique described in the papers by Tinti et al. (1994) and by Tinti and Gavagni (1994). The basin is covered by a grid of triangles, created by a mesh building code which is particularly suitable to match coastlines with complicated pattern of bays and promontories and to optimise the triangle quality measured in terms of triangle isotropy and crossing times (see criteria of mesh building for tsunami equations solvers in Tinti and Bortolucci, 1999).

The tsunami is calculated around Stromboli by means of a local grid covering the rectangular region shown in Fig. 1. The mesh consists of 6210 nodes and 11886 triangles with an average crossing time of about $1.59 \mathrm{~s}$ and a characteristic length of about $40-50 \mathrm{~m}$ in the vicinity of the island coasts. The simulation has run for a period of $1000 \mathrm{~s}$ with an integration time step of $0.5 \mathrm{~s}$. The large volume collapse expectedly generates very big waves that propagate from the source and travel around the island. The main signal is formed by a large positive leading front that is followed by an even larger trough, that in turn is followed by a second crest. The water elevation fields computed at intervals of $50 \mathrm{~s}$ and portrayed in Fig. 5 help understand the main features of the propagation. At $t=50 \mathrm{~s}$ (upper left panel of Fig. 5) the slide is moving around its peak speed and has already generated a well pronounced positive front (larger than $10 \mathrm{~m}$ ) with a deep 

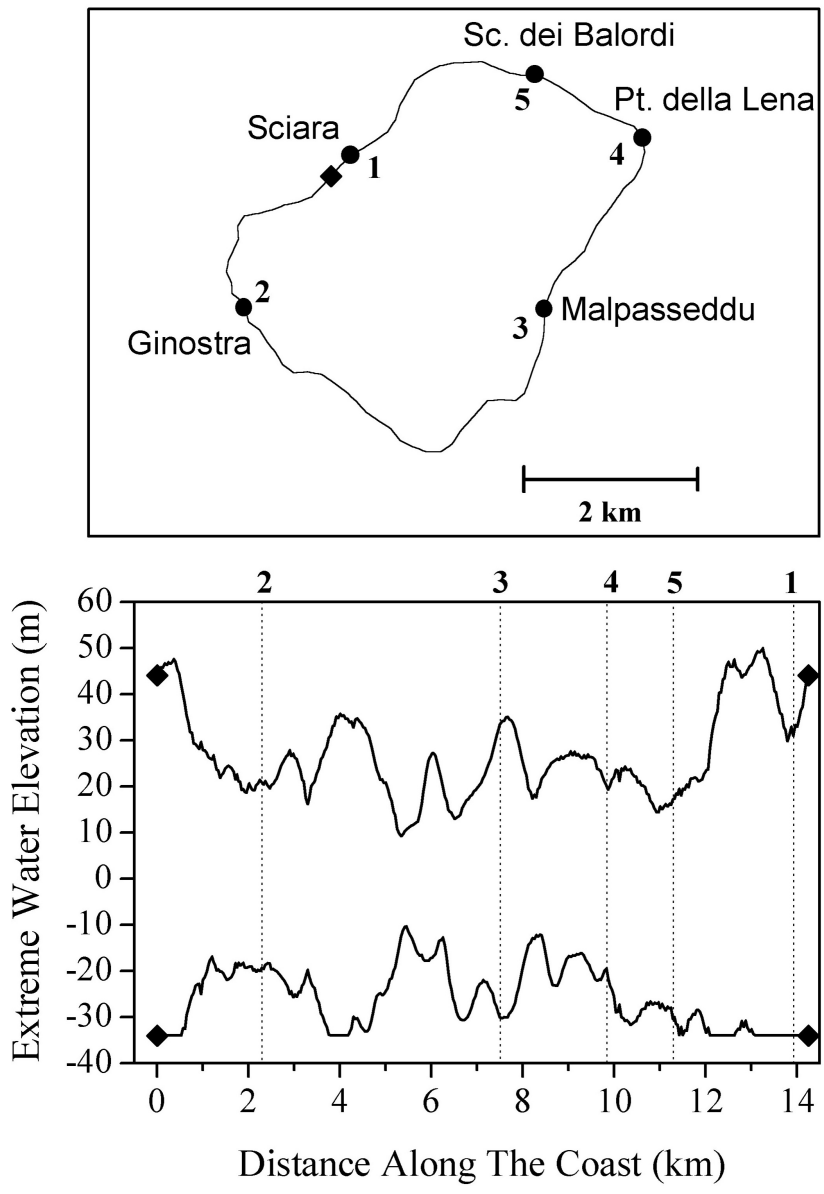

Fig. 7. Maximum and minimum water elevation values computed on the coasts of Stromboli plotted vs. distance. This is measured along the curvilinear coastline counterclockwise from the starting point (solid diamond), that is arbitrarily taken to be to the west of the Sciara del Fuoco.

trough (exceeding $30 \mathrm{~m}$ ). High and low water levels are quite close each other, and consequently the wave is very steep. At $t=100 \mathrm{~s}$ the leading front is leaving the computational domain, and a new crest is forming close to the SdF. The intermediate trough is now well formed and dominates the graph. The snapshots corresponding to later times show that the main perturbation has left the domain, but a set of edge waves has formed around the islands and travel slowly since they propagate in shallow waters: at $t=150 \mathrm{~s}$ the tsunami has not yet reached the coasts opposite to the $\mathrm{SdF}$, that is circa $7 \mathrm{~km}$ from the source, though has already travelled a much larger distance in the offshore direction where the ocean is deeper than $2000 \mathrm{~m}$. The formation of edge waves around conic islands is not surprising. The capability of such islands of trapping the energy of waves that possess length comparable with the typical island size and that either approach the island from remote sources or are generated locally has been long explored and nowadays well ascertained (see Tinti and Vannini, 1994, 1995).

Synthetic tide-gauge records computed in the locations marked with a solid circle in the map of Fig. 5 are plotted in Fig. 6. The characteristic sequence of crest-trough-crest is clear only in the the marigram calculated in the node that is placed in the open sea along the path of the landslide (lower right panel). Coastal time histories are more complex. Notice that at the $\mathrm{SdF}$ the first big negative-positive oscillation is the most remarkable feature, while at Malpasseddu on the lee side of the island the main wave system is formed by a double trough sandwiching a very large crest. Notice further that in all records the transition from low to high level or from high to low level is as large as several tens of metres and occurs in a very short time (a few tens of seconds), which means that the main waves are very steep and that a virtual observer would see an impressive wall of water attacking the coasts of Stromboli. Figure 7 shows the minimum and maximum values of the water elevation calculated along the coastline. Observe that the highest waves (about $50 \mathrm{~m}$ ) are computed in the proximity of the landslide area, that most of the island coast experiences waves larger than $20 \mathrm{~m}$ and that in some places such as Malpasseddu the largest waves exceed $30 \mathrm{~m}$, because of the constructive interference of edge waves travelling around the island along opposite paths. It is relevant to point out that our model does not compute the run-up of the waves, that is it does not compute the propagation of the waves that climb beyond the usual shoreline and flood the land above the sea level. The computational coastal boundary is formed by vertical walls that reflect the waves perfectly (in our run the depth of the coastal nodes of Stromboli has been assumed to be $35 \mathrm{~m}$ ). Therefore we are able to compute only the maximum and minimum water height. It is known that these extreme values are quite useful, though they provide usually underestimates of the sea water run-up and draw-down (Kanoglu and Synolakis, 1998; Lin et al., 1999; Li and Raichlen, 2001).

\section{The Tsunami in the south-east Tyrrhenian sea}

The tsunami propagation in the south-eastern Tyrrhenian sea and in the northern part of the Messina Strait has been studied by means of a mesh covering the region shown in the geographical map of Fig. 1. The grid is formed by 25126 nodes and more than 48000 triangles having an average crossing time of $14.6 \mathrm{~s}$. The grid includes more elements than the one utilised for the near-source simulation, but has nonetheless a much coarser resolution: the length of its triangles ranges between $200 \mathrm{~m}$ for near-shore shallow-depth triangles and more than $1500 \mathrm{~m}$ for larger offshore triangles with a distribution modal value of about $400 \mathrm{~m}$. The simulation is carried out for a computation time of $2000 \mathrm{~s}$ with an integration time step of $1 \mathrm{~s}$. The water elevation fields depicted in Fig. 8 are given at intervals of $200 \mathrm{~s}$ and enable one to understand the propagation of the tsunami. The snapshot of the upper left corner is taken at the same time $(t=200 \mathrm{~s})$ as the field calculated over the smaller grid and shown in Fig. 5. Here the complete wave system can be seen, and it can be noticed that the perturbation tends to split into a double system, one radiating outward and 

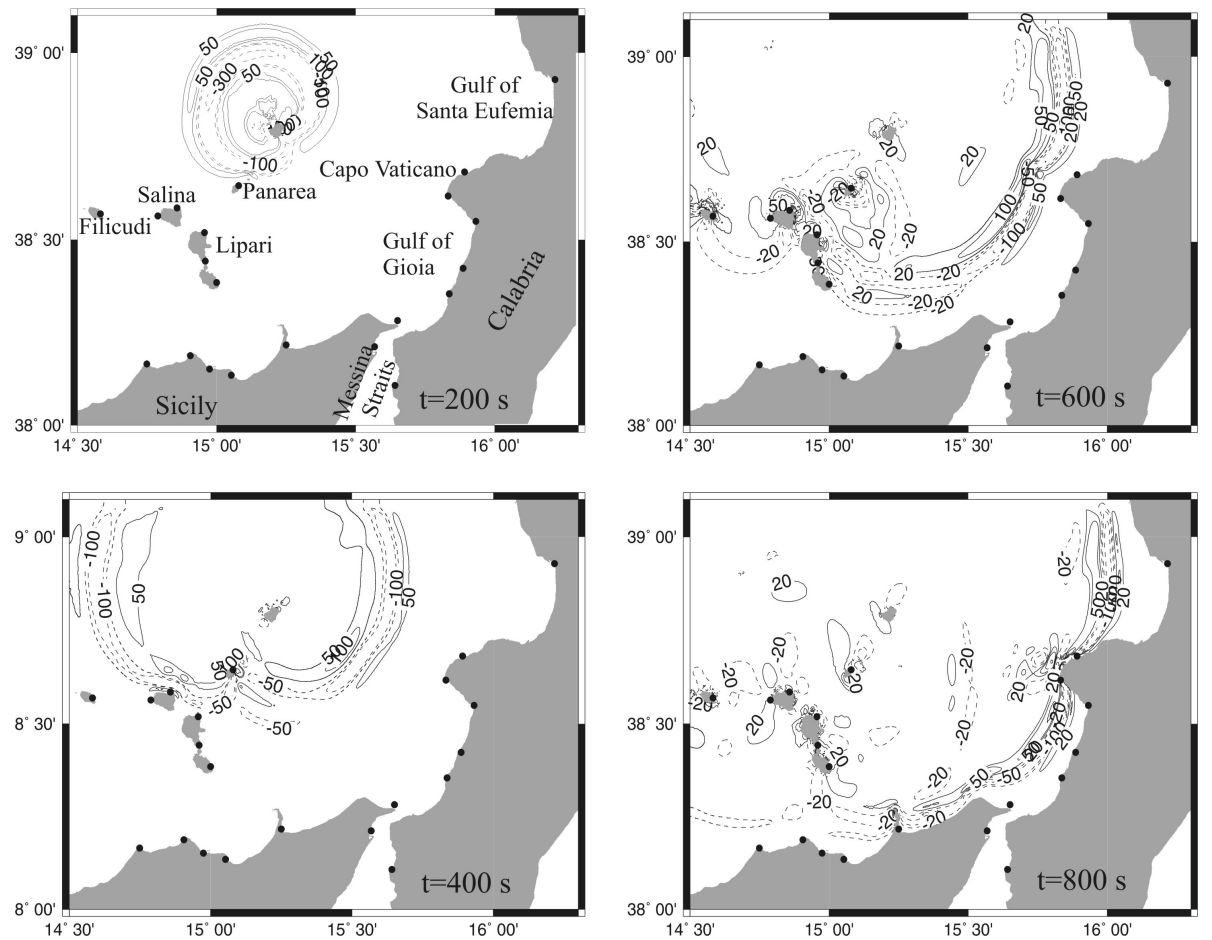

Fig. 8. Water elevation fields in the south-east Tyrrhenian sea computed at intervals of $200 \mathrm{~s}$. Contour lines are labeled in $\mathrm{cm}$.

one trapped in the shallow water belt around Stromboli. The outer system is attacking the neighbouring island of Panarea and advances with almost circular fronts. At $t=400 \mathrm{~s}$ the tsunami has already passed the northern and western boundaries of the grid. The circular front can be still seen clearly, though it deforms while interacting with Panarea, that has been just passed, and with Salina and Lipari, that are under attack. It may be also distinctly observed that the leading wave system consists of two crests separated by a large intermediate trough, and that it is followed by a tail of more irregular oscillations. The further fields after $t=600 \mathrm{~s}$ and $t=800 \mathrm{~s}$ show that the tsunami travels beyond the island arc, passing first through the channel between Salina and Filicudi, and exciting local edge-wave systems that persist around each of the islands. The south western sector of the tsunami front looses energy interacting with the Aeolian islands. On the other hand, the south-eastern sector advances toward Calabria and Sicily with no obstacle interposed and at $t=800 \mathrm{~s}$ the attack on the main land has already begun. The bathymetry influences its propagation by focussing it strongly against the Calabrian promontory of Capo Vaticano and defocussing it from the Messina Strait.

Figure 9 shows the tide-gauge time histories computed on coastal stations placed in the Aeolian islands, the location of which can be seen in the general map of Fig. 1. The largest oscillations having height of about $8 \mathrm{~m}$ are computed for the records of Panarea and east Salina, that are the first islands close to Stromboli to be attacked by the tsunami. Notice the big difference between east and west Salina marigrams, which is easily explainable since the former faces the advanc- ing front of the tsunami, while the latter is on the opposite side of the island: it is screened from the direct attack and affected by the local system of trapped waves that is however weaker than the leading front. The waves calculated for the other tide gauges are quite smaller having amplitudes of about one half. Figures 10 and 11 give the lowest and largest water elevation computed along the coasts of Sicily and of Calabria respectively. Almost all the coastline comprised between Capo d'Orlando and Milazzo in northern Sicily is attacked by waves of about $1 \mathrm{~m}$. This value increases gradually moving eastward from Milazzo to Punta Faro and attains the largest heights of about $5 \mathrm{~m}$ slightly west of Punta Faro. Notice that in the rightmost part of the plot of Fig. 10 the extreme values computed beyond Punta Faro, corresponding to the Sicily coasts of the Messina Strait, are very low (only a few tens of $\mathrm{cm}$ ). Figure 11 confirms that the tsunami is very modest in the Strait (see the leftmost portion of the graph), but it shows also that on average Calabria is attacked by larger waves than Sicily. The only segments of coastline with waves around $1 \mathrm{~m}$ are found south of Palmi and halfway between Tropea and Lamezia in the central coast of the Gulf of Santa Eufemia. Oscillations are in the range of 2-5.5 $\mathrm{m}$ in the stretch of coast north of Lamezia, and attain the largest values on the coasts around Capo Vaticano, that separates the Gulf of Santa Eufemia (to the north) from the Gulf of Gioia (to the south). Here the values exceed $2 \mathrm{~m}$ in the area that is found just north of the promontory, are remarkably larger $(>3 \mathrm{~m}$ ) south of the cape between Palmi and Nicotera, and reach the peak values of about $8 \mathrm{~m}$ just in correspondence with the tip of the headland. This is the manifest conse- 

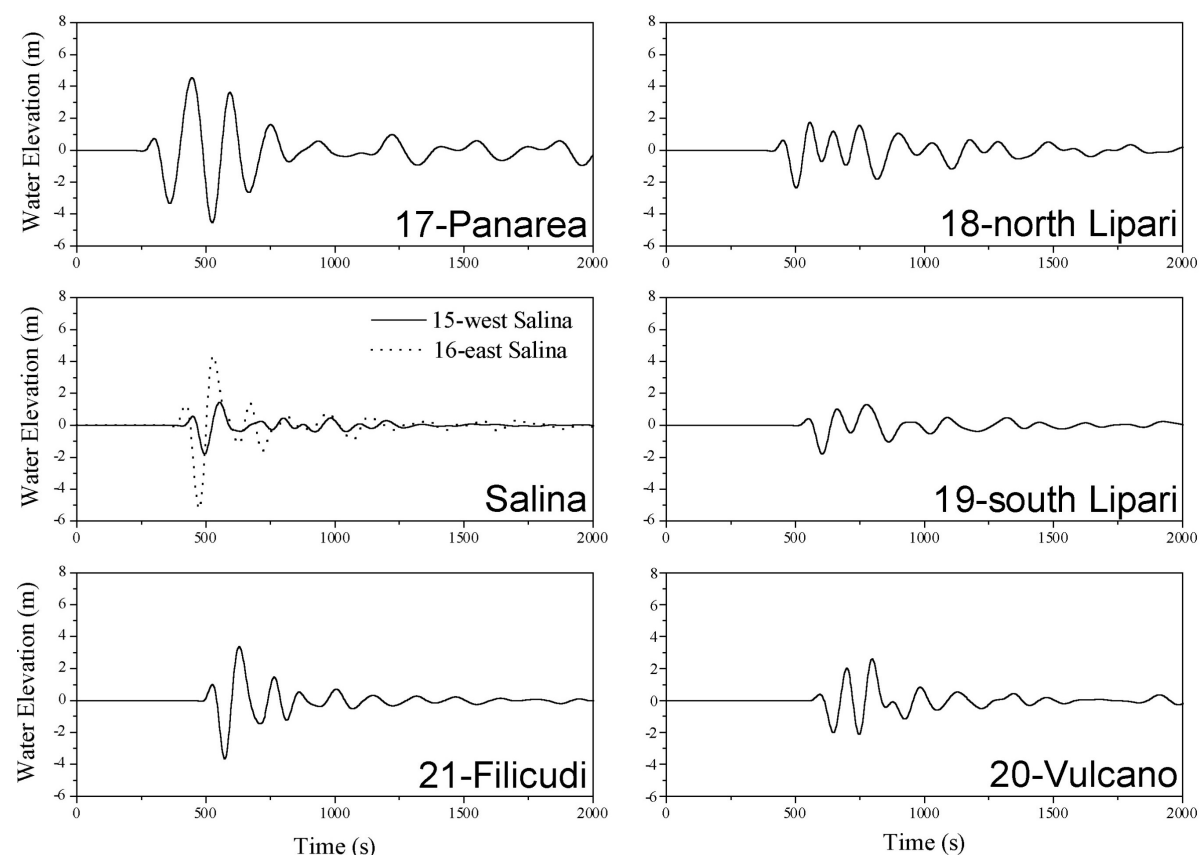

Fig. 9. Tide-gauge records computed for coastal stations placed in the Aeolian islands. The large-field tsunami simulation has been run for $2000 \mathrm{~s}$.

quence of the focussing of the wave front, that was already observed on looking at fields of Fig. 8, and that is essentially due to the bathymetric features around the cape. As is clearly visible in the Tyrrhenian sea bathymetry portrayed in Fig. 1, the promontory continues for several kilometers underwater down to a depth of $1000 \mathrm{~m}$ (compare the $1000 \mathrm{~m}$ and $500 \mathrm{~m}$ isobaths offshore the cape).

\section{Conclusions}

In this paper we have examined the tsunamis that can be generated by Stromboli volcano. Historical accounts of Stromboli eruptions do not go back more than 500 years, but they can be considered complete only in the last 120 years, since the beginning of modern volcanological studies. The known tsunamis are all associated with eruptions included in the complete portion of the Stromboli eruption data set. They occurred concomitantly with the major explosions of Stromboli, and generally are events with damaging potential for local structures, but not in the far field. Here they can produce only slight oscillations of the sea level detectable by instruments, but likely to pass unnoticed by people. Albeit the association of tsunamis and volcanic activity is certain, the generating mechanism of the tsunami is unclear, except for waves killing some people in 1930 that were undoubtedly produced by hot avalanches entering the sea north of San Bartolo in the northern coast. This lack of understanding is a drawback that has to be overcome and future research should explore the possible direct causes of the tsunami, focusing at least on two possible mechanisms. The conjecture that they are due to small submarine landslides mobilised by the eruptions should be verified by on-field investigations aiming at finding the plausibility of sediment accumulation taking place at shallow sea depth on the marine flanks of the volcanic cone all around the island and at quantifying their thickness and stability. The further hypothesis that tsunamigenesis is due to the overpressure induced on the sea surface by the collapse of the eruptive column (invoked by Ponte, 1921 to explain the 1919 tsunami) should also be tested by numerical models combining the simulation of the formation, ascent and collapse of the column with the simulation of the ensuing tsunami. An example of such modeling applied to exploring the tsunami potential of light pyroclastic flows moving seaward from the Vesuvius crater is provided by the work by Tinti et al. (2003).

Very big tsunamis can be generated at Stromboli by the lateral collapse of the volcanic edifice. These are extraordinary events that are quite likely on the geological time scale, since they repeated at least four times in the last $13 \mathrm{ka}$, with features that are more or less similar. They involved the northwestern flank with typical volumes on the order of $1 \mathrm{~km}^{3}$. The last one was the responsible of the present scar named Sciara del Fuoco that collects all the present activity ejecta, channelling them to the sea. We have modelled the landslide by means of a numerical code based on the Lagrangian approach, that considers the sliding body as a linear chain of contiguous interacting blocks and computes the motion of all the blocks, that is assumed to occur along a common prescribed path. We take the same body geometry, the same sliding surface geometry and the same physical parameters to describe the forces acting on the blocks that were used in previous simulations performed by Tinti et al. (2000), and 

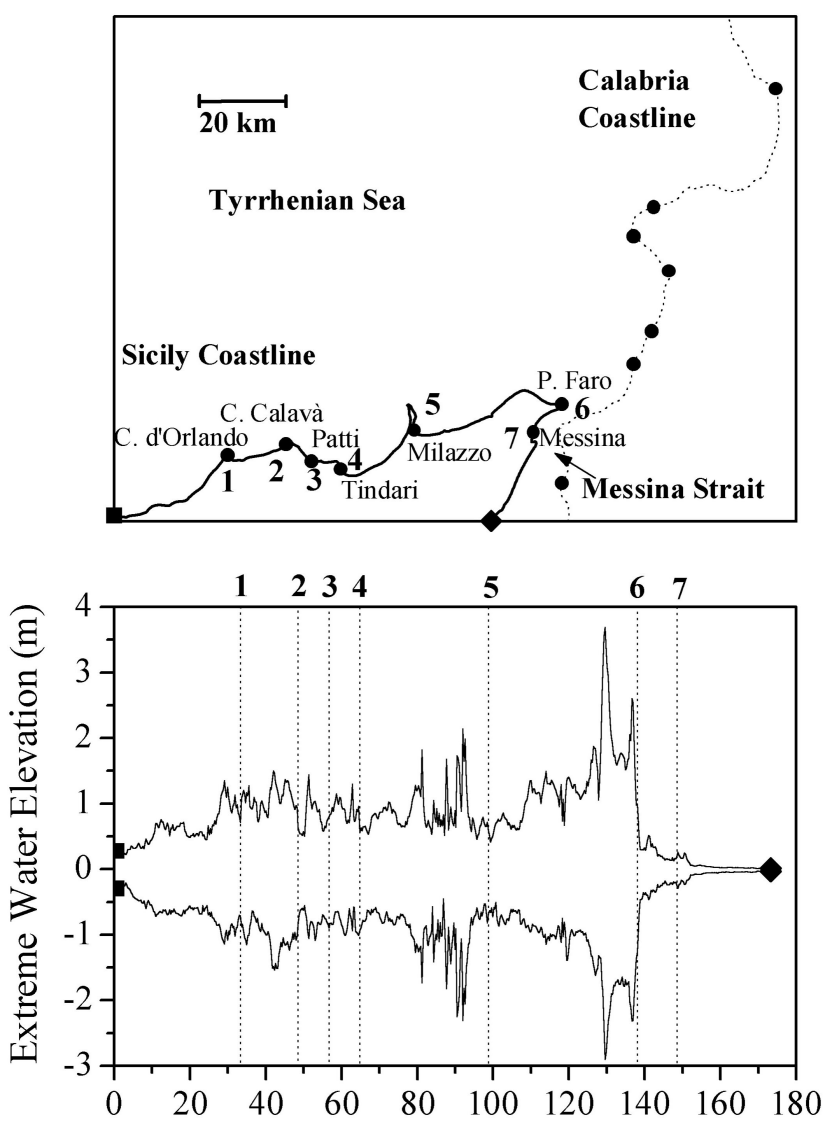

Distance Along The Coast $(\mathrm{km})$

Fig. 10. Extreme water elevations computed on the Sicily coasts vs. distance, which is measured eastward along the coastline from the point marked with a solid square to the point marked with a solid diamond.

make use of an enhanced version of the numerical code. The results obtained here are expectedly quite close to the previous finding: the slide is very fast and reaches a speed of more than $60 \mathrm{~m} / \mathrm{s}$ in about $40 \mathrm{~s}$, keeping it for the next $60 \mathrm{~s}$ and then slowing down gradually. Sensitivity analysis performed by Tinti et al. (2000) showed that varying the dissipation coefficient give rise to faster or slower slides, but that the feature of a body experiencing a large positive acceleration at the intial stage and then a comparatively smaller negative acceleration is common to all cases.

The tsunami has been studied in the near-field around Stromboli by solving the longwave hydrodynamic equations over a very fine grid with a resolution much better than the one used in previous computations (the number of nodes and elements is more than doubled). The main finding confirms that the tsunami generated has the potential to cause a large catastrophe along the Stromboli coasts. The main features of the near-field tsunami can be summarised in the following points:

1. The most efficient tsunamigenic phase is the first stage
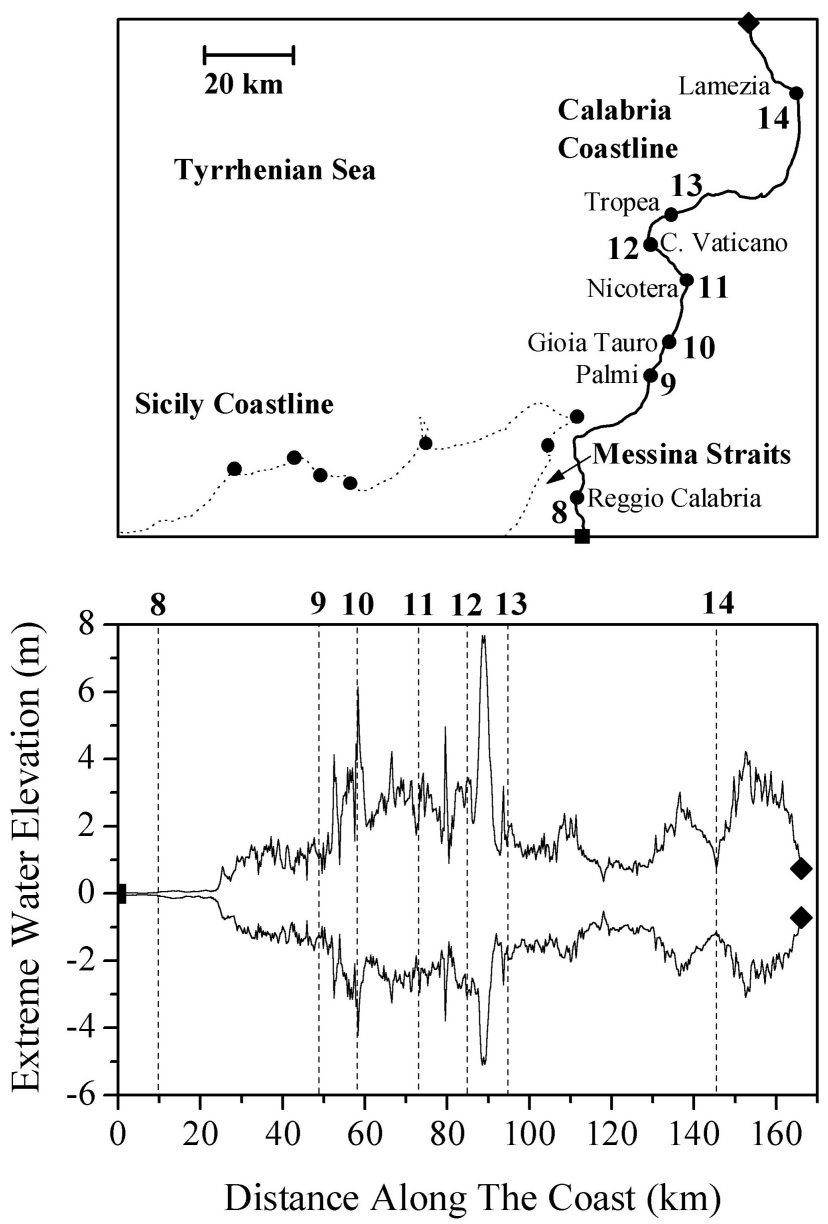

Fig. 11. Extreme water elevations computed on the Calabria coasts vs. distance, which is measured northward along the coastline from the point marked with a solid square to the point marked with a solid diamond.

of the body motion, when the underwater displacement occurs at shallow depth, and two favouring factors concur simultaneously: (i) the body speed is approaching the longwave celerity (and the Froude number approaches the critical value of (1); (ii) the transfer function, allowing one to compute the forcing term from the transient bottom topography changes induced by the landslide, is not too far from unity.

2. The main system of waves radiates outward from the source and moves at high speed offshore. Its typical signature offshore is the sequence of a positive leading crest, a larger trough and a second smaller crest.

3. The tsunami travels around the island of Stromboli very slowly in form of a set of edge waves with very steep fronts, that give rise to a long tail of oscillations in the computed marigrams.

4. The maximum positive and negative signals are computed in the northwestern coast, which is the one involved by the collapse. The entire coastline is attacked 
by giant waves with height larger than $20 \mathrm{~m}$ and exceeding $60 \mathrm{~m}$ in some places between Ginostra and Malpasseddu.

The propagation of the tsunami in the ocean waters far from Stromboli has been simulated by using a coarser grid embracing the whole south-eastern Tyrrhenian basin and the northern part of the Messina Strait. The main results can be listed as follows:

1. The main front of the tsunami tends to radiate in circular fronts. This observation is relevant and is distinctive of a tsunami generated by a landslide, that is by a source that moves at speed lower than or of the same order as the wave celerity. Tsunamis produced by earthquakes, i.e. by ocean floor displacements that propagate very fast and that can be taken as instantaneous processes, are characterised by very strong directivity effects, with lobe-like frontal pattern and most energy radiation occurring in the direction normal to the source fault.

2. Departure from circular radiation is due to the ocean bathymetry. The distortion of the front is relevant in the interaction with the Aeolian islands and with the submarine foot of the promontory of Capo Vaticano.

3. Panarea and Salina are the first islands to be attacked by the tsunami circa $230 \mathrm{~s}$ and $400 \mathrm{~s}$ after the collapse inception, and here the computed tsunami waves reach the largest height in the whole archipelago (excluding Stromboli).

4. The tsunami excites a system of trapped waves around each island, loosing therefore part of its energy. The tsunami propagates beyond the island arc, but it is much weaker after crossing it, and consequently the archipelago can be seen as a natural shield from the tsunami for the northwest Sicily coasts.

5. The tsunami reaches Sicily and Calabria in about 800 $900 \mathrm{~s}$. On average, Sicily is attacked by waves smaller than Calabria. Waves with height around $4-6 \mathrm{~m}$ are computed for most of the Calabria coasts, but the area most affected results to be around the head of the Capo Vaticano promontory where the simulation gives wave height in excess of $10 \mathrm{~m}$. Focusing of sea waves produced by headlands is well known, but the effect here is particularly powerful because Capo Vaticano begins influencing the advancing front when it is still well offshore approximately in correpondence with the $1000 \mathrm{~m}$ isobath.

6. The coasts of the Messina Straits are almost unaffected by the tsunami. The defocusing of the front caused by the bathymetry in combination with the narrow and shallow northern mouth of the sea channel prevent the longwave to enter the Straits waters.

The analysis computed by the present paper has shown that the chief tsunami potential for Stromboli derives from lateral collapses associated with giant eruptions of the volcano. The huge-volume landslide is capable of setting in motion a regional tsunami that may cause total destruction of all human activities in Stromboli, and may cause large destruction in the neighbouring islands of Panarea and Salina within a few minutes. Within $12-15 \mathrm{~min}$ the tsunami attacks the Sicily and Tyrrhenian Calabria coasts with powerful waves that are expected to be particularly dangerous in the area of Capo Vaticano. The estimates of wave heights and travel times are relevant to devise emergency and evacuation plans associated with a scenario of volcanic giant eruption of Stromboli.

Acknowledgements. This work was carried out on funds from the Gruppo Nazionale di Vulcanologia (GNV) of the Istituto Nazionale di Geofisica e Vulcanologia (INGV). The authors thank all the groups cooperating in the special GNV project on the Hazard Associated with Stromboli Volcano for useful discussions, and are especially greatful to M. Rosi from the University of Pisa, Italy, and to A. Tibaldi from the University of Milan-Bicocca, Italy.

\section{References}

Abbruzzese, D.: Sulla catastrofica esplosione dello Stromboli dell' 11 settembre del 1930, Atti Accademia Gioenia di Sci. Nat., Catania, 1, 1-33 (in Italian), 1936.

Ambraseys, N. N.: Data for investigation of seismic sea waves in the Eastern Mediterranean, Bull. Seism. Soc. Am., 52, 895-913, 1962.

Barberi, F., Rosi, M., and Sodi, A.: Volcanic hazard assessment at Stromboli based on review of historic data, Acta Vulcanologica, 3, 173-187, 1993.

Gillot, P. Y. and Keller, J.: Radiochronological dating of Stromboli, Acta Vulcanol., 3, 69-77, 1993.

Imbò, G.: Catalogue of the active volcanoes of the world including Solfatara Fields, Italy, 18th IAV, Rome, 1965.

Kanoglu, U. and Synolakis, C. E.: Long wave runup on piecewise linear topographies, J. Fluid Mech., 374, 1-28, 1998.

Kidd, R. B., Lucchi, R. G., Gee. M., and Woodside, J. M.: Sedimentary processes in the Stromboli canyon and Marsili Basin, SE Tyrrhenian sea: results from side-scan sonar surveys, GeoMarine Lett., 18, 146-154, 1998.

Kokelaar, P. and Romagnoli, C.: Sector collapse, sedimentation and clast population evolution at an active island-arc volcano: Stromboli, Italy, Bull. Volcanol., 57, 240-262, 1995.

Li, Y. and Raichlen, F.: Solitary wave runup on plane slopes, J. Waterway Port Coastal and Ocean Engineering, ASCE, 127, 3344, 2001.

Lin, P. Z., Chang, K. A., and Liu, P. F. L.: Run up and run down of solitary waves on sloping beaches, J. Waterway Port Coastal and Ocean Engineering, ASCE, 125, 247-255, 1999.

Mercalli, G.: Natura delle eruzioni dello Stromboli ed in generale dell'attività sismo-vulcanica delle Isole Eolie, Atti Soc. Ital. Sci. Natur., 27, 184-199 (in Italian), 1881.

Mercalli, G.: Osservazioni fatte allo Stromboli nel settembre 1888 e nel febbraio-marzo 1889, Annali dell'Ufficio Centrale di Meteorologia e Geodinamica, 10, 177-186 (in Italian), 1891.

Platania, G.: L'esplosione dello Stromboli del maggio 1919, Boll. Accademia Gioenia Sci. Nat., Catania, 50, 1-17 (in Italian), 1922. 
Ponte, G.: La formidabile esplosione dello Stromboli del 1916, Mem. R. Com. Geol. It., 7, 1-34 (in Italian), 1921.

Riccò, A. and Mercalli, G.: Sopra il periodo eruttivo dello Stromboli cominciato il 24 giugno 1891, Annali dell'Ufficio Centrale di Meteorologia e Geodinamica, 11, 189-221 (in Italian), 1892.

Rittmann, A.: Der Ausbruch des Stromboli am 11 September 1930, Zeitschrift für Vulkanologie, 14, 47-77 (in German), 1931.

Rosi, M., Bertagnini, A., and Landi, P.: Onset of the persistent activity at Stromboli volcano, Bull. Volcanol., 62, 294-300, 2000.

Tibaldi, A.: Multiple sector collapses at Stromboli volcano, Italy: how they work, Bull. Volcanol., 63, 112-125, 2001.

Tibaldi, A., Pasquarè, G., Francalanci, L., and Garduno, V. H.: Collapse type and recurrence at Stromboli volcano, associated volcanic activity, and sea level changes, Accademia dei Lincei, Atti Convegni dei Lincei, Rome, 112, 143-151, 1994.

Tinti, S., Gavagni, I., and Piatanesi, A.: A finite-element numerical approach for modelling tsunamis, Annali di Geofisica, 37, 10091026, 1994.

Tinti, S. and Gavagni, I.: A method for reducing the propagation noise in FE modeling of tsunamis, Science of Tsunami Hazards, 12, 77-92, 1994.

Tinti, S. and Vannini, C.: Theoretical investigation on tsunamis induced by seismic faults near ocean islands, Marine Geodesy, 17, 193-212, 1994.

Tinti, S. and Vannini, C.: Tsunami trapping near circular islands,
Pure Applied Geophys., 144, 595-619, 1995.

Tinti, S. and Maramai, A.: Catalogue of tsunamis generated in Italy and in Côte d'Azur, France: a step towards a unified catalogue of tsunamis in Europe, Annali di Geofisica, 39, 1253-1299 (Errata Corrige, Annali di Geofisica, 40, 781), 1996.

Tinti, S., Bortolucci, E., and Vannini, C.: A block-based theoretical model suited to gravitational sliding, Natural Hazards, 16, 1-28, 1997.

Tinti, S., Bortolucci, E., and Piatanesi, A.: Un modello Lagrangiano per lo studio della dinamica delle frane, Atti del Conv. Intern. sulla Prevenzione delle Catastrofi Idrogeologiche: il Contributo della Ricerca Scientifica, Alba, Italy, 5-7 November 1996, 549557 (in Italian), 1998.

Tinti, S. and Bortolucci, E.: Strategies of optimal grid generation for finite-element tsunami models, Proc. International Conference on Tsunamis, Paris, 26-28 May 1998, 269-294, 1999.

Tinti, S., Bortolucci, E., and Armigliato, A.: Numerical simulation of the landslide-induced tsunami of 1988 on Vulcano island, Italy, Bull. Volcanol., 61, 121-137, 1999.

Tinti, S., Bortolucci, E., and Romagnoli, C.: Computer simulations of tsunamis due to flank collapse at Stromboli, Italy, J. Volcanol. Geoth. Res., 96, 103-128, 2000.

Tinti, S., Pagnoni, G., and Piatanesi, A.: Simulation of tsunamis induced by volcanic activity in the Gulf of Naples (Italy), this issue, 2003. 